\title{
Cultura visual e curadoria em museus de História
}

\author{
SOLANGE FERRAZ DE LIMA* \\ VÂNIA CARNEIRO DE CARVALHO*
}

\begin{abstract}
Resumo: O artigo apresenta experiências acadêmicas e museológicas envolvendo as coleções fotográficas do Museu Paulista de São Paulo/Brasil. Nosso objetivo é demonstrar a ligação orgânica existente entre as três áreas constitutivas da prática curatorial: a produção de um sistema documental, a produção de conhecimento na área da cultura visual e a produção de obras dedicadas ao público de um museu de história.

Abstract: The article presents academic and museological experiments involving the photographic collections of the Paulista Museum of the University of São Paulo/Brazil. Our aim is to demonstrate the organic liaison that there is among the three constitutive curatorship practices: the production of a documental system, the production of knowledge in the area of visual culture and the production of work dedicated to the public of a museum of history.
\end{abstract}

Palavras-chave: Fotografia. Museus de História. Curadoria.

Key words: Photography. Museums of history. Curatorship.

\section{A curadoria}

Desde 1990, tem sido preocupação central dos curadores dos acervos históricos do Museu Paulista tornar a pesquisa acadêmica no campo da cultura material o eixo de desenvolvimento de trabalhos de cultura e extensão. No que diz respeito aos acervos fotográficos, houve mudanças nos procedimentos de aquisição de coleções, que se direcionaram para conjuntos significativos tanto na sua quantidade como na qualidade de informações preservadas.

Nossa atividade de curadoras do acervo iconográfico do $\mathrm{Mu}$ seu Paulista ${ }^{1}$ nos levou a pensar no potencial do banco de imagens

Museu Paulista da USP.

1 O acervo do Serviço de Documentação Textual e Iconografia do Museu Paulista conta hoje com mais de 47.000 unidades iconográficas, sendo a maioria fotografias.

Estudos Ibero-Americanos. PUCRS, v. XXXI, n. 2, p. 53-77, dezembro 2005 
como plataforma para os estudos que procuram demonstrar como a forma é parte estruturante e, portanto, indissociável da produção do sentido. Igualmente, a compreensão da natureza histórica do consumo e produção de imagens implica ampliar o escopo dos sistemas de documentação para além de descrições genéricas. Instituições como os museus, que gerenciam acervos iconográficos, são o lugar privilegiado para a implantação de sistemas documentais que contemplem a especificidade da imagem, pois uma História da Visualidade se faz através da pesquisa que analisa a imagem como parte da prática social.

No caso da produção fotográfica, a pesquisa articula-se aos sistemas documentais institucionais, que, entre muitas outras tarefas, estariam voltados para a geração de um vocabulário descritivo que atendesse essas especificidades. Atualmente, os programas de recuperação de imagem são capazes de selecionar segundo atributos formais - cores, texturas, fisionomias (bibliotecas de retratos de personalidades são indexadas automaticamente, o reconhecimento facial pode ser aplicado na identificação de procurados pela polícia, busca-se uma paisagem com determinadas cores que combinem como o produto ou cartaz publicitário). Curiosamente, o estudo formal de imagens nesta área vem atender a demandas extremamente simples e convencionais (busca por assunto, acontecimento, personalidade). O usuário passa ao largo da sofisticação e da percepção que um pequeno grupo de técnicos desenvolve com relação à imagem. ${ }^{2}$ Cabe a nós, pesquisadores das ciências humanas, fornecer os elementos necessários para que o repertório formal das imagens possa ser compreendido e utilizado pedagogicamente em experiências que extrapolam o âmbito restrito da academia. A demanda hoje por imagens deve vir acompanhada de um esforço de crítica da imagem. Cremos que essa crítica não dispensa a compreensão dos elementos formais que a constituem.

2 Sobre as experiências na montagem de descritores icônicos para acesso sem intermediação lingüística ver Beth Sandore (ed.). Library Trends, v. 48, n. 2, p. 496-520, 1999; HEIDORN, P. Bryan Heidorn. Image Retrieval as Linguistic and Nonlinguistic Visual Model Matching. Library Trends, v. 48, n. 2, p. 303-325, 1999; Brendan Cassidy. Iconography in Theory and Practice. Visual Resources, v. 11, p. 323-348, 1996; HsinLiang Chen; Edie M. Rasmussen. Intellectual Access to Images. Library Trends, v. 48, n. 2, p. 291-302, 1999; William Allen. Teaching Composition Digitally. Visual Resources, v. 15, n. 1, p. 65-74, 1999; Howard Besser. Visual Access to Visual Images: The UC Berkeley Image Database Project. Library Trends, v. 38, n. 2, p. 787-98, 1990. Um dos pioneiros foi certamente Henri Hudrisier. L'iconothèque: documentation audiovisuelle et banques d'images. Paris: Documentation Française,1982. 


\section{A paisagem urbana}

Nossa primeira experiência acadêmica com a montagem de um vocabulário que permitisse descrever as características formais da fotografia aconteceu durante os estudos de mestrado. Ao analisarmos um conjunto de 1.600 fotografias da cidade de São Paulo, entre os anos de 1860 e 1954, demonstramos como as noções de cidade eram construções concretas e não apenas sentidos impalpáveis inferidos da presença de certos conteúdos iconográficos como a natureza de determinados edifícios ou tipos humanos. Para chegarmos ao desenho dos conceitos de cidade reunimos e adaptamos uma nomenclatura, estabelecida principalmente no campo das artes plásticas. Através de um vocabulário formal, aplicado a cada documento, chegamos às combinações mais recorrentes, ou seja, ao repertório visual do conjunto documental analisado. Só então nos foi possível demonstrar como esse repertório visual estava associado a sentidos socialmente produzidos e aderidos às imagens. ${ }^{3}$

A análise das fotografias de São Paulo ao final do século XIX e primeiras duas décadas do século XX nos mostrou que a cidade é concebida como o espaço de circulação de mercadorias. A valorização da rua em primeiro plano exagerado não é acidental, ou simples efeito estético. Efeitos de ordenação não são produzidos pela simples presença, por exemplo, do guarda de trânsito, mas por efeitos visuais de repetição regular de formas geométricas como aqueles produzidos pela vegetação ou pelas pedras de pavimentação. Os elementos figurativos são centralizados e explorados na sua simetria e monumentalidade. $\mathrm{O}$ dinamismo formal das linhas diagonais não rompe o equilíbrio de uma composição perspéctica que valoriza a contigüidade dos planos, os pontos de fuga no infinito e a distribuição eqüitativa nos quadrantes da imagem. A presença de edifícios públicos e infra-estrutura urbana nos mostra um espaço sob o domínio do Estado, que imprime na cidade as marcas de uma racionalidade açambarcadora. Nas fotografias dos anos de 1950, os padrões visuais vão nos indicar uma outra concepção de cidade, onde a rua deixa de ser a vedete, os efeitos visuais de regularidade, simetria e equilíbrio são substituídos por formas caóticas de distribuição, as edificações (agora privadas ou financeiras como os edifícios de apartamento e bancos) são repre-

3 Para uma apreciação extensa da análise das imagens de São Paulo ver CARVALHO, Vânia Carneiro de; LIMA, Solange Ferraz de. Fotografia e cidade: da razão urbana à lógica do consumo. Álbuns de São Paulo (1887-1954). São Paulo: Mercado de Letras, 1997. 
sentadas de forma fragmentada, a contigüidade dos planos é substituída pelo arranjo por sobreposição etc. Como vemos, a apreensão dos recursos visuais da imagem não teve como objetivo criar novos meios de acesso a esse tipo de documento, como vem sendo o caso de documentalistas que se dedicam ao assunto há décadas. Nossa intenção era articular o estudo dos atributos formais da imagem a determinadas problemáticas históricas.

A primeira experiência completa da linha curatorial acima proposta aconteceu em 1993. O estudo sobre o uso de fotografias da cidade de São Paulo como "modelo" para a produção de telas de pintura que integrariam a decoração do edifício do Museu a partir de 1922 forneceu as diretrizes para a montagem de exposição e, posteriormente, para a edição de um vídeo didático, que serviram para apresentar problemas formais e representacionais nas imagens da cidade para visitantes, professores e alunos de cursos de extensão oferecidos pelo Museu.

A análise comparativa dos suportes fotográfico e pictórico revelou uma preocupação em construir uma imagem de cidade colonial para São Paulo a partir da inclusão, substituição ou reforço daqueles elementos considerados emblemáticos do período colonial brasileiro. Assim, são incluídos, nas telas, elementos que não figuravam nas fotografias, como é o caso do tropeiro, e dos tipos sociais característicos do período. Os índices de modernização da cidade, que podem ser flagrados nas imagens fotográficas, como é o caso da carruagem estacionada no Largo S. Bento ou da presença de uma mulher conversando com um homem trajado de sobretudo e cartola (uma indumentária, sem dúvida, de uso urbano) são substituídos nas pinturas. A carruagem cede lugar ao carro de boi e o casal é substituído por um tropeiro e um guarda, tendo ao fundo muares carregados, numa menção às tropas que atravessavam a cidade vindo do interior. Algumas características da arquitetura colonial, como os longos beirais e os muxarabis, presentes nas imagens fotográficas são enfatizados nas pinturas, seja por um desenho mais detalhado, seja pela representação de áreas de sombra decorrente dos beirais avançados. A transposição dos registros fotográficos para os suportes pictóricos resulta, assim, em uma reciclagem de sentido. Se nas fotografias procura-se enfocar uma embrionária modernização da cidade, a série pictórica promove o contrário, ou seja, a torna arcaica. O repertório plástico e temático do período colonial é facilmente identificado nas pinturas (as tropas e a figura do tropeiro, a arquitetura vernacular, o carro de boi) atendendo ao projeto museológico e pedagógico de Taunay de reconstituição de uma cidade arcaica e colonial, anterior à expan- 
são decorrente do sucesso com a lavoura cafeeira, em fins do século XIX. Essa análise iconográfica permitiu o desenvolvimento de questões relativas ao papel da visualidade como suporte para as funções pedagógicas e celebrativas desempenhadas pelo Museu Paulista sob a direção de Affonso de E. Taunay.

\section{O retrato}

Trabalhando no mesmo quadro conceitual e metodológico acima apresentado, tivemos a oportunidade de estender o tratamento formal a um conjunto de aproximadamente 12.000 retratos fotográficos através de descritores inseridos na base de dados institucional. Os retratos foram produzidos por um único fotógrafo, Militão Augusto de Azevedo, que atuou na cidade de São Paulo entre os anos de 1862 e 1885, uma época em que sua população não chegava aos 40.000 habitantes. ${ }^{4} \mathrm{O}$ fotógrafo é conhecido pelos estudiosos da cidade de São Paulo em virtude dos registros fotográficos urbanos que realizou, dando origem ao Álbum Comparativo da $\mathrm{Ci}$ dade de São Paulo, 1862-1887. A sua atividade como retratista, no entanto, foi pouco divulgada para além do circuito da história da fotografia no Brasil e a documentação a ela relacionada permaneceu praticamente inédita, em posse da família até 1996, quando passou a integrar os acervos do Museu Paulista da USP. Militão nasceu no Rio de Janeiro em 1837. Aos 25 anos veio para São Paulo e aqui se estabeleceu, trabalhando como retratista na filial do ateliê carioca Carneiro \& Gaspar. Em 1875, Militão, já sócio do estabelecimento, adquire o estúdio e passa a denominá-lo Photographia Americana. Nos seus 20 anos de atuação, o ateliê recebeu clientes ilustres e anônimos: o Imperador D.Pedro II, a Imperatriz Teresa Cristina, Castro Alves, Joaquim Nabuco, Amaral Gurgel, José Maria Lisboa, Frei Germano de Annecy, primeiro astrônomo de São Paulo, artistas de companhias teatrais que na cidade faziam suas temporadas, funcionários públicos e liberais como médicos, advogados, engenheiros, trabalhadores anônimos, escravos e alforria-

4 Sobre Militão ver Cândido Domingues Grangeiro. As artes de um negócio: a febre photographica. São Paulo, 1862-1886. Campinas: Fapesp/Mercado de Letras, 2000; Boris Kossoy. Militão Augusto de Azevedo e a documentação fotográfica de São Paulo (1862-1887): recuperação da cena paulistana através da fotografia. São Paulo, 1978. Dissertação (Mestrado); Ilka Brunhilde Laurito. Retratos de um photographo. In: São Paulo em três tempos: álbum comparativo da cidade de São Paulo (1862-1887-1914). São Paulo: IMESP, 1982; Benedito Lima de Toledo e Boris Kossoy. São Paulo: álbum comparativo da cidade de São Paulo. 1862-1887. São Paulo: s.e., 1981; Pedro Corrêa do Lago. Militão Augusto de Azevedo. Rio de Janeiro: Capivara e Marca d'Água, 2001. 
dos, o primeiro barbeiro, o professor de piano, a engomadeira, a prostituta, pessoas com deformações físicas, cadáveres, inúmeras crianças, casais, mães com bebês, homens e mulheres que formam um imenso painel de tipos humanos no século XIX. Ao fechar seu estúdio, em 1885, Militão se desfaz do laboratório, leiloando máquinas, materiais e apetrechos fotográficos, mas mantém a documentação textual e iconográfica. A maior parte da documentação que compõe a Coleção Militão Augusto de Azevedo é formada pelos livros de controle e mostruário dos dois estúdios, e que trazem mais de 12.000 retratos, produzidos originalmente no formato carte-de-visite e cabinet-portrait.

Dos milhares de retratos, somente quatro centenas estão identificadas pelo próprio Militão. Como tantos corpos e rostos anônimos poderiam se tornar interessantes para a pesquisa? Mais do que na paisagem urbana, nossa conhecida, os milhares de retratos de Militão interessam pelo modo como os indivíduos se apresentam - são rostos, roupas, telas pintadas ao fundo, mesas, cadeiras, poltronas, espelhos, colunas, esculturas, tapetes e posturas corporais. O que mais temos aqui são composições, formas estruturadas, recorrentes, com variações notáveis de gênero, faixa etária, cor da pele, lugar social. Pareceu-nos evidente que, apesar de se tratar de um banco de imagens institucional, o que significa aberto para todo o tipo de visitante e, portanto, desvinculado de qualquer formulação de hipótese científica, não era possível deixá-lo sem uma descrição de seus atributos visuais.

Assim, decididos somar aos dados convencionais a indicação dos objetos cenográficos e a descrição das poses dos retratados. Pensamos com isso não ter ultrapassado a fronteira, muitas vezes tênue, entre aquilo que são as qualidades formais presentes na fotografia e os sentidos a ela atribuídos. O estudo dos sentidos cabe ao pesquisador, que, munido de problemáticas específicas, mobiliza os atributos formais para entender como estes foram interpretados pela sociedade, não apenas no momento de sua produção, mas nos diferentes modos de apropriação e circulação da imagem.

Tentamos oferecer ao usuário do banco de imagens do Museu Paulista, predominantemente pesquisadores e estudantes de graduação e pós-graduação, dados primários que deveriam ser posteriormente trabalhados por eles. Ao mesmo tempo, a equipe da casa se beneficiaria de um projeto que dava um passo adiante no 
enfrentamento de uma documentação que deveria nos servir para o estudo do retrato na perspectiva da cultura material. ${ }^{5}$

As informações levantadas a partir do controle de variáveis da coleção permitiram observar como se constituem materialmente e como se articulam duas categorias fundamentais - a identidade social e a identidade de gênero (masculino/feminino). A constituição de noções de individualidade e identidade não podem prescindir da mobilização de próteses materiais que são os objetos de decoração, os elementos arquitetônicos e as partes do próprio corpo. Se considerarmos o circuito dos elementos visuais do retrato fotográfico, veremos que a sua ocorrência não se restringe ao espaço do estúdio do fotógrafo, mas integra-se a uma lógica maior, determinada por regimes visuais que organizam os sentidos específicos da distinção social e de gênero na cultura da cidade. ${ }^{6}$

Com a aplicação dos descritores que distinguem sexo e faixa etária para o conjunto de 12.178 retratos, verificamos predominância da presença masculina adulta $(60 \%)$. Mais do que isso, metade

5 Sobre o retrato fotográfico oitocentista no Brasil ver Joaquim Marçal Andrade (org). A Coleção do Imperador: Fotografia brasileira e estrangeira no século XIX. Rio de Janeiro: Biblioteca Nacional, 1997; Ana Maria Mauad de Andrade Essus. Sob o signo da imagem. Rio de Janeiro, 1990. Tese (Doutorado) - Universidade Federal Fluminense e da mesma autora Resgate de Memórias. In: Hebe Mara Mattos e Eduardo Schnoor (Orgs.). Resgate: uma janela para o Oitocentos. Rio de Janeiro: Topbooks, 1995, p. 99138; Gilberto Freyre. Por uma sociofotografia. In O retrato brasileiro: fotografias da Coleção Francisco Rodrigues 1840-1920. Rio de Janeiro: Funarte/Fundação Joaquim Nabuco, 1983. p. 15-24;

Fundação Joaquim Nabuco. O sujeito em perigo: identidade fotográfica e alteridade no Brasil do século XIX até 1940. Recife: FUNDAJE/Ed. Massangana, 1992; Boris Kossoy e Maria Luiza Tucci Carneiro. O olhar europeu: o negro na iconografia brasileira do século XIX. São Paulo: Edusp, 1994; Miriam L. Moreira Leite. Retrato de casamento. Literatura e Memória Cultural: Anais, v. 1. Belo Horizonte, Abralic, 1991, p. 335-351; Maurício Lissovsky e Paulo César Azevedo (Orgs.). Escravos brasileiros do século XIX na fotografia de Christiano Júnior. São Paulo: Ex-Libris, 1988; Miriam Paula Manini. Análise documentária de fotografias: um referencial de leitura de imagens fotográficas para fins documentários. São Paulo: Escola de Comunicações e Artes da USP, 2002. Tese de (Doutorado); Pedro Vasquez. O retrato brasileiro. Rio de Janeiro: Funarte/Núcleo de Fotografia, 1983 (Catálogo de exposição); Carlos Eugênio Marcondes de Moura (org.). Retratos quase inocentes. São Paulo: Nobel, 1983.

6 A historiadora Ana Maria Mauad Essus desenvolveu uma metodologia de análise fotográfica que guarda muitas semelhanças na abordagem dos aspectos formais do retrato com a análise morfológica que propomos. Em seu estudo sobre a coleção de retratos oitocentista da família Valim e Almeida, pertencente à elite cafeeira do interior do Estado de São Paulo, Essus procedeu a um tratamento estatístico usando categorias que evidenciaram a predominância dos retratos masculinos sobre os femininos e, no que se refere ao enquadramento, a absoluta preferência pelo busto masculino. Cf. ESSUS, Ana Maria Mauad. Resgate de Memórias. In: Eduardo Schnoor e Hebe Maria Mattos de Castro. Resgate, um janela para o oitocentos. Rio de Janeiro: Topbooks, 1995, p. 99-138. 
de todo o conjunto apresenta o homem sozinho, contra um número de retratos femininos exclusivos que não chega à marca dos $20 \%$. Mesmo considerando meninos e meninas, onde os números são mais equilibrados, a representação masculina na infância ainda é mais numerosa. Se fotografar-se era um gesto socialmente significativo, ele deve ser entendido também como um gesto sexualmente ativo.

Em um universo de milhares de imagens encontramos apenas raros exemplares que ousaram associar a sua imagem a instrumentos de trabalho como a pá, a panela ou o serrote. Parece-nos que, numa cidade onde a grande massa da população masculina era pobre, flutuante e ligada aos trabalhos manuais (comércio ambulante, artesanato e serviços urbanos e domésticos em geral), ${ }^{7}$ produzir um retrato usando terno, colete e calça como partes de um mesmo conjunto, além de complementos como cartola, guardachuva, bengala e óculos significava distanciar-se dos segmentos sociais desprestigiados e construir uma imagem (real ou ficcional) de respeito e dignidade, que era sinônimo de homens cuja profissão e situação financeira permitiam a adoção da indumentária urbana européia.

No caso dos retratos de corpo inteiro, os homens apresentamse em posição ereta, de frente, com leve rotação do corpo ou do rosto para a esquerda ou direita, e apoiados em objetos que também dão à sua imagem significados específicos como veremos. Em comparação com os tempos atuais, os rostos masculinos expõemse com grande riqueza de cortes de cabelos, tipos de barba e bigodes, que serão ainda mais destacados nas imagens de busto, que tendem a ganhar espaço ao longo do século XX. Esta tipologia de postura e gesto não se restringe ao retrato de estúdio e é possível verificarmos a sua recorrência nas fotografias de parques e jardins, espaços privilegiados, no século XIX, de visibilidade do homem e cuja freqüência exigia posturas corporais definidas pela etiqueta da convivência em espaços públicos abertos. Ao isolarmos determinadas posturas e enquadramento e associá-las ao gênero masculino e feminino cercamos os elementos de uma sintaxe cujo sentido se completa no âmbito de uma cultura visual que envolve não só a circulação própria do retrato, mas de um modelo masculino de fruição da cidade. Neste sentido, o retrato é resultado e ao

Cf. Maria Inez Machado Borges Pinto. Cotidiano e sobrevivência: a vida do trabalhador pobre na cidade de São Paulo, 1890-1914. São Paulo: Edusp / Fapesp, 1994. 
mesmo gerador de uma linguagem corporal que dá materialidade para práticas sociais específicas. ${ }^{8}$

A representação da mulher nas imagens de corpo inteiro tem diferenças significativas. Observamos que no enquadramento do cartão de visita o vestido amplo salienta os quadris em composição com a cadeira, ${ }^{9}$ criando um peso maior nos dois quadrantes inferiores da imagem. Tal volume compete com os elementos que figuram nos quadrantes superiores, especialmente com o rosto. $\mathrm{O}$ vestido possui grande riqueza formal e como se não bastasse, é apenas entre os retratos femininos que observamos a presença de poses completamente laterais em que se destacam intensamente as linhas do corpo, como as curvas da nuca e da lombar, elementos que competem fortemente com o rosto. Nesses retratos é possível identificar os mesmos atributos presentes na noção de mulherornamento, difundida nos manuais de economia doméstica e etiqueta dos séculos XIX e XX, ou seja, da mulher de sala, refinada e de bom gosto, capaz de qualificar a posição social supostamente elevada do marido.

Dentre os retratos da coleção que se apresentam integralmente (sem recorte), 1080 são individuais de corpo inteiro (759 masculinos e 391 femininos). Este universo pode ser analisado com especial atenção à participação dos ornamentos na sintaxe formal. Usando como vetor os descritores relativos à postura, dois grandes grupos podem, de imediato, ser identificados: as poses de corpo inteiro sentado e aquelas de corpo inteiro em pé. Para ambos os sexos predomina a pose em pé $(86 \%$ entre os retratos masculinos e $85 \%$ entre os retratos femininos). As variantes de postura associadas aos acessórios cenográficos permitem considerações interessantes. Pedestal ou coluna, balaustrada, um bloco de pedra provavelmente confeccionado de papier maché, cadeira, poltrona, mesa, bibelôs (estatueta e vasos) e painéis pintados integram o repertório de objetos cênicos controlados através dos descritores. A cenografia em foco guarda suas raízes nas matrizes dos retratos pintados do século XVIII, sobretudo no caso dos elementos arquitetônicos vinculados à gramática clássica, como a coluna, o pedestal ornado com vasos e o candelabro em estilo grotesco que constitui um dos motivos dos painéis de fundo. A presença da ornamentação clássica remete a uma associação cultivada pela aristocracia européia

8 Cf. Solange Ferrraz de Lima. Ornamento e Cidade - ferro, estuque e pintura mural em São Paulo, 1870-1930. São Paulo, FFLCH/USP, 2002. Tese (Doutorado).

9 Mais de $40 \%$ das imagens femininas têm a presença da cadeira, cujo espaldar serve de apoio para as mão na posição ereta. 
que a faz eqüivaler às noções de requinte e bom gosto. Esvaziados daqueles sentidos específicos que motivaram a composição nas pinturas dos nobres participantes do Grand Tour, ${ }^{10}$ esses ornamentos permanecem como significantes (elementos plásticos, formas) na composição do retrato fotográfico, cumprindo, no entanto, outras funções e sendo resignificados por novas práticas urbanas e grupos sociais burgueses em ascensão - distinção entre trabalho manual e intelectual, introdução ao mundo cosmopolita e moderno, elegância, etc.

Nos retratos de corpo inteiro, os elementos cênicos são claramente selecionados em função da postura adotada. A pose, por sua vez, é escolhida pelo retratado segundo motivações diversas, mas sempre associada à sua imagem pública. Na segunda metade do século XIX, a emergência e complexificação das cidades colocou em evidência o poder da ornamentação arquitetônica em distinguir edifícios no tecido urbano e, mais do que isso, explicitar o poder econômico dos proprietários de residenciais luxuosas e ornamentadas nos preceitos do que se considerava de bom gosto neste período, ou seja, o neoclássico. São Paulo, que vive o seu primeiro surto de crescimento e afluência de capitais no último quartel do século XIX, começa a ter suas feições alteradas por loteamentos e residências de alto padrão. Para estas residências, a ornamentação das fachadas baseava-se em colunatas, frisos e vasos, emoldurando janelas e portas e criando, visualmente, enquadramentos semelhantes àqueles do retrato fotográfico. Na cultura

10 O contexto para a introdução da arquitetura clássica como aparato ornamental do retratado é bem específico e tem como matriz principal os retratos produzidos por Pompeu Batoni (1708-1787). Batoni, como tantos outros pintores italianos, estabeleceu-se em um nicho particular de mercado vinculado ao movimento conhecido como o Grand Tour. Em meados do século XVIII, a Itália torna-se uma grande escola para a formação clássica da nobiliarquia européia. As recentes descobertas arqueológicas de Pompéia e Herculano atraíam milhares de nobres, principalmente ingleses e alemães. Este turismo cultural rendeu toda sorte de cultura material na forma de souvenirs - desde fragmentos arqueológicos até retratos pintados por artistas que tinham seus ateliês em Nápoles, Roma e Florença e os produziam no espírito de lembrança de viagem. Batoni tornou-se o preferido retratista entre nobres ingleses. Muito embora ele tenha produzido inúmeros retratos no formato busto, seu estilo consagrou-se com o retrato de corpo inteiro, tendo como elementos ornamentais de composição da pose a paisagem de fundo retratando as ruínas arqueológicas e partes da arquitetura clássica. Embora não tenha sido Batoni a criar esta associação, ele tornouse o favorito entre a aristocracia por perseguir a semelhança em suas representações, expressa em cores fortes, o que o diferenciava de seus contemporâneos e predecessores. Os clientes de Batoni valorizavam o seu desenho acurado e "realista" nos detalhes da composição de corpo inteiro. Sobre o assunto, ver Anthony Clark. Pompeo Batoni - a Complete Catalogue of his Works with an Introductory Text. London: Phaidon, 1985 e David Irwin. Neoclassicism. London: Phaidon, 1997, p. 26. 
visual de uma sociedade emergente como a que tratamos, a visibilidade pública do indivíduo se faz representar por elementos arquitetônicos presentes nas fachadas das residências burguesas, transmudados em cenografia de estúdio. Não é por acaso que, em $70 \%$ das poses eretas de corpo inteiro, o pedestal, a coluna e a balaustrada (elementos presentes nas fachadas residenciais) ou, ainda, a pedra cenográfica (elemento presente nos parques e passeios públicos) compõem o cenário.

Por outro lado, a pose sentada é associada ao interior residencial, dada a presença de mobiliário próprio da sala de visitas. ${ }^{11} \mathrm{O}$ interior burguês transforma-se em uma experiência possível a partir do estúdio fotográfico, numa época em que quase nenhuma casa assimilara a idéia de sala de visitas como espaço de representação de status, ostentação e negociação social. ${ }^{12}$ Os retratos de casais articulam-se a essa nova modalidade pública na casa, mas nos mostram como homens e mulheres a vivenciaram de modo diferente. No caso dos retratos de casal (634 ao todo), quase metade $(48 \%)$ são de homens e mulheres em pé. No entanto, o segundo padrão mais recorrente é aquele em que a mulher aparece em pé e o homem sentado. Além do acesso masculino privilegiado à cadeira, as imagens de grupos masculinos nos indicam uma maior riqueza de posturas corporais que variam entre a extremamente rígida até aquela completamente informal - pernas relaxadamente abertas, uso da mesa como assento ou encosto, corpo recostado etc. Tais retratos nos dão os primeiros indícios da importância do sentar-se na constituição da identidade masculina, a qual cria ligações explícitas com as noções de conforto corporal e poder.

A pose em pé está associada aos elementos ornamentais do exterior da residência. Na rua e na exposição à janela a postura ereta seria o padrão. O paralelo entre a tipologia de ornamentos presente no estúdio e na fachada reforça esta associação. Seja na fachada, no estúdio ou mesmo na pintura mural, os ornamentos objetuais e figurativos organizados no padrão aditivo $^{13}$ são aqueles que ficam

11 Carlos Lemos em seu artigo Ambientação Ilusória (In: Carlos Eugênio Marcondes de Moura (Org.). Retratos quase inocentes. São Paulo: Nobel, 1983, p. 61) chama a atenção para o fato do mobiliário dos estúdios brasileiros ser, na maioria, rebuscado poltronas de veludo, entalhados ao gosto mais europeu: "O interessante é que esses ambientes, confinados nos ateliês, talvez por terem sido imaginados e trazidos pelos fotógrafos de seus países de origem, nunca reproduzem interiores comuns às casas brasileiras. [...] nunca vemos ali uma simples cadeira Luiz Felipe de palhinha trançada, ou uma prosaica poltrona austríaca, já tão em moda".

12 Carlos Lemos, op. cit., p. 57-58.

13 O padrão ornamental aditivo caracteriza-se pelo uso de motivos que não se repetem e nem são simétricos. 
mais próximos dos indivíduos. É interessante notar que são desta tipologia os ornamentos aos quais são mais facilmente atrelados sentidos de ordem cívica e celebrativa.

No caso de São Paulo, o retrato parece ter cumprido um papel estratégico nas mudanças de mentalidade quanto ao uso do artefato doméstico e arquitetônico. A introdução do artifício e dos recursos artísticos na casa não era uma prática tão disseminada entre a população paulistana no período de atuação de Militão como fotógrafo. E certo que São Paulo começava a perder suas feições coloniais, onde a casa era mobiliada com parcimônia e funcionalidade. A partir da estrada de ferro, dos investimentos na reurbanização e das construções de moradias refinadas da elite enriquecida pelo café e ávida por se modernizar, urbanizar e diversificar seus negócios, ${ }^{14}$ inicia-se um primeiro derrame de produtos importados para a construção dos ambientes decorativos domésticos (e, supomos, também comerciais). Quando Militão fecha as portas de seu ateliê em 1885, no entanto, esse processo estava apenas no seu início. Será nas primeiras duas décadas do século $X X$ que assistiremos, em São Paulo, à difusão de uma cultura material voltada para a decoração de residências inclusive dos segmentos médios. ${ }^{15}$ Provavelmente, para a maioria dos retratados de Militão, a experiência no ateliê fotográfico era a primeira oportunidade de se verem introduzidos em um ambiente decorado com os ícones do refinamento da burguesia citadina. Com o retrato nas mãos muitos paulistanos pobres ou remediados puderam ter uma pequena materialização das noções de dignidade, opulência e bom gosto apli-

14 Cf. Carlos Alberto Cerqueira Lemos. Casa Paulista: história das moradias anteriores ao ecletismo trazido pelo café. São Paulo: Edusp, 1999; Maria Cristina Wolff de Carvalho. Bem-morar em São Paulo, 1880-1910: Ramos de Azevedo e os modelos europeus. Anais do Museu PaulistaErro! Indicador não definido.. São Paulo, v.4, p.165-200 jan./dez. 1996; Maria Cecília Naclério Homem. O palacete paulistano e outras formas urbanas de morar da elite cafeeira. 1867-1918. São Paulo: Martins Fontes, 1996; Flávio Azevedo Marques de Saes. O campo da economia. Cadernos de História de São Paulo: os campos do conhecimento e o conhecimento da cidade. n. 1. São Paulo: Museu Paulista da USP, 1992. p. 25-35; Carlos Alberto Cerqueira Lemos. Alvenaria burguesa breve história da arquitetura residencial de tijolos em São Paulo a partir do ciclo econômico liderado pelo café. 2. ed. São Paulo: Nobel, 1985; Ernani Silva Bruno. História e tradições da cidade de São Paulo. São Paulo: Hucitec, 1984; Jurandir Freire Costa. Ordem médica e norma familiar. 2. ed. Rio de Janeiro: Graal, 1983; Benedito Lima de Toledo. São Paulo, três cidades em um século. São Paulo: Duas Cidades, 1981; Luís Saia. Morada paulista. São Paulo: Perspectiva, 1972.

15 Sobre o papel do sistema decorativo na constituição do espaço doméstico paulistano ver Vânia Carneiro de Carvalho. Gênero e artefato: o sistema doméstico na perspectiva da cultura material. São Paulo: Depto de História da FFLCH-USP, 2001. Tese (Doutorado). 
cadas à sua figura. No estúdio fotográfico eles foram estimulados a sonhar com uma nova vida. Afinal, o desejo por ascensão social está na base do consumo de mercadorias, processo no qual, acreditamos, a fotografia teve papel estruturante. Os clientes desejavam uma imagem de alto valor pessoal. Aquela "boa" figura gerada no estúdio circularia por várias mãos, integraria os álbuns de família, os porta-retratos de amigos e parentes distantes, suplantaria, com alguma sorte, a vida de seu referente. Era preciso, portanto, deixar de lado qualquer espontaneísmo ou realismo comprometedor e construir algo que fosse digno de permanência. Nesse sentido, a solenidade dos retratos fotográficos que observamos nos álbuns de Militão e nos cartões e gabinetes dessa época em muito se assemelham à pintura. ${ }^{16}$

O uso de descritores na explicitação de padrões formais do retrato fotográfico teve uma primeira versão tridimensional na exposição São Paulo nas lentes de Militão, inaugurada em 1997,17 onde através de um painel interativo de cubos giratórios o visitante poderia perceber as poses mais recorrentes, apresentadas em conjuntos de retratos diferentes com poses semelhantes. Ao girar os cubos os visitantes os colocavam em posições variadas e acabavam, orientados por cores, chegando aos conjuntos.

\section{Cultura visual: entre arte e história}

Para nós estava clara a relação orgânica entre o sistema documental e a pesquisa. O próximo passo seria dado a partir do interesse do artista plástico Gavin Adams em associar à problemática do retrato (padrões de pose, produção seriada,construção de identidades sociais) as experiências estéticas produzidas a partir de imagens em movimento. Da conjugação de conhecimentos de duas áreas - Artes Plásticas e História da Cultura Material, projetamos para o público visitante do museu obras que não se reduzi-

16 Da análise da série inferimos mudanças de mentalidade manifestas em inovações de composição, como é o caso dos retratos de reis franceses após a inovação introduzida por Hyacinthe Rigaud (1659-1743), que decide retratar Louis XIV em pose propositadamente mais informal do que era praticado até então. Ele inaugurou um estilo que se perpetuou por toda a dinastia real a partir de então. Uma inovação que vira cânone graças a mudanças e aspirações específicas da realidade social daquele momento. Peter Burke, op. cit., p. 28.

17 A exposição "São Paulo nas Lentes de Militão Augusto de Azevedo" foi aberta ao público em maio de 1997. Curadoria de Solange Ferraz de Lima e Vânia Carneiro de Carvalho. Pesquisa e Documentação de Regina Teles, Cláudia Moi, Renata Garbellini, Montserrat Moreno. Concepção visual e Desenho gráfico de Ana Helena Curi, Cláudia Warrak (designer), Fábio Montenegro e Fernando Rodrigues (arquiteto). 
am à tradicional tentativa de "tradução" simplificada, por isso entendida como pedagógica, do conhecimento produzido por especialistas.

Nosso objetivo foi articular as problemáticas históricas ligadas à fotografia oitocentista com conceitos e linguagens oriundos das artes plásticas através de dispositivos visuais e tridimensionais tratados em ambiente expositivo no espaço de um museu de história. A categoria Museu Histórico enfrenta hoje dilemas relativos ao desempenho das exposições frente aos seus objetivos educacionais, culturais e de fruição estética. Diante do uso por vezes quase abusivo de recursos de multimídia e imagens eletrônicas e em face das cenarizações dos parques temáticos que forjam um passado estilizado com o qual o espectador se relaciona acriticamente, quais seriam os caminhos para o museu histórico conciliar curadorias de natureza científica, propósitos educacionais e prazer estético? Espaço pontencialmente disponível para a fruição estética e para o contato do público com as reflexões desenvolvidas na sua área de especialização, a exposição histórica sofre tanto com a ausência de um fluxo contínuo entre pesquisa e curadoria, quanto com a falta de experiências estéticas associadas a temas de natureza histórica. Oscila entre os extremos de tornar-se atração turística esvaziada de conteúdos críticos e a opção de manter-se distante de qualquer incorporação de meios tecnológicos associados aos projetos museográficos. A aproximação entre Artes Plásticas e História da Cultura Material resultou em fertilizações mútuas. De um lado, o artista plástico foi introduzido em um vasto território documental e a uma produção científica apropriada apenas entre seus pares. Por outro lado, a curadoria histórica pode contar a experiência do artista na realização plástica de obras que sintonizavam reflexões atuais com problemáticas desenvolvidas nos moldes textuais da academia. 


\section{Poses do $19^{18}$}

O vídeo Poses do 19 foi o primeiro produto dessa conjugação de esforços entre historiadores e artistas multimídia. A produção do vídeo mobilizou 1338 retratos no formato carte-de-visite (pouco mais de $10 \%$ do total de retratos existentes na Coleção Militão Augusto de Azevedo). ${ }^{19}$ Após a digitalização das reproduções dos retratos originais, cada imagem foi alinhada na altura dos olhos do retratado e reenquadrada numa espécie de gabarito de moldura para igualar o ponto de referência capaz de garantir os efeitos de animação na seqüência em movimento. Todo o trabalho realizado em ilha de edição digital. A trilha sonora foi desenvolvida especialmente para o vídeo e resulta de colagens de samples, distorções sonoras que visam, conceitualmente, abordar o caráter de reprodutibilidade técnica e mecânica que marcou o século XIX. Assim, são sublinhadas as mudanças cenográficas, posturais, sexuais e etárias. Tonalidades e frases-título funcionam como agrupadores dos núcleos visuais e conceituais relevantes. Cada cartão de visita foi considerado um fotograma de um filme de animação. A consistência e interesse plástico do conjunto derivava do grupos tipológicos detectados como recorrentes no sistema documental. As imagens foram agrupadas segundo semelhanças visuais: homens de pé ao lado de balaustrada à direita (com mão na cintura, com mão sobre a balaustrada, com guarda-chuva, com bengala, com chapéu), ho-

18 O vídeo Poses do 19 (9 min.) Direção artística, edição e trilha sonora de Gavin Adams; direção científica e roteiro de Solange Ferraz de Lima e Vânia Carneiro de Carvalho; finalização da Espaço Digital; produção do Museu Paulista da Universidade de São Paulo, Fundo de Pesquisa do Museu Paulista / Usp e Espaço Digital com o apoio da Sociedade Amigos do Museu Paulita - Sampa. O vídeo recebeu o Grand Prix Ciném'Art du Court Métrage no Festival Audiovisual Internacional Museus $\mathcal{E}$ Patrimônio - International Council of Museums (AVICOM), em novembro de 2002, participou da seleção oficial do Tenth Annual San Diego Latino Film Festival, San Diego/EUA(2003), do Festival Latino-Americano de Cinema e Vídeo/Cinesul (2003) e da seleção para Programação Paralela no 14 Festival Internacional de Arte Eletrônica Videobrasil (2003).

19 O formato fotográfico denominado cartão de visita possui aproximadamente $9 \times 6 \mathrm{~cm}$ e foi inventado pelo fotógrafo Disdéri em 1854, em Paris. O pequeno formato tornou o retrato mais barato e popular e foi sucesso absoluto no mundo inteiro. Sobre Disdéri ver a obra de Elizabeth McCauley, A. A. E. Disdéri and the Carte de Visite Portrait Photograph (1985). Trata-se de um bem sucedido estudo sobre o retrato fotográfico que procura imbricar uma trajetória particular, matrizes visuais e circuito social. Partindo de um estudo de caso biográfico McCauley fornece um quadro consistente das práticas do consumo deste produto fotográfico, isolando os seus gêneros de maior apelo mercadológico - os retratos de personagens célebres da sociedade da época, as séries de retratos de artistas, etc. Ao mesmo tempo, a autora preocupa-se em investigar como os aspectos técnicos da fotografia juntamente com a tradição formal advinda da pintura influíram na composição formal da carte-de-visite. 
mens de pé ao lado de balaustrada à esquerda (com mão na cintura, com mão sobre a balaustrada, com guarda-chuva, com bengala, com chapéu), homens de pé junto a poltrona à direita (com mão na cintura...), e assim por diante. Grandes grupos organizados segundo gêneros e faixa etária e a partir das poses e objetos cenográficos recorrentes foram subdivididos em padrões visuais mais finos como posição das mãos, direção do olhar, volumetria proporcionada pelo estatura e indumentária, etc. Colocados em movimento, os retratos sofrem uma quase fusão, própria da seqüência animada, resultando na predominância da retórica das poses sobre as figuras individuais. Marca-se a tensão presente no retrato feito em escala industrial, do qual o cartão de visita é seu melhor exemplar, ou seja, aquela entre o indivíduo e o estereótipo.

\section{A instalação Animatoscópio 20}

A instalação Animatoscópio, concebida para integrar a exposição Olho Cíclico, alimenta-se da experiência do vídeo Poses do 19 e amplia suas possibilidades. A animação agora justapõe um universo total de $3.200^{21}$ retratos fotográficos produzidos por Militão no formato cartão de visita e cabinet-portrait. Ao contrário do vídeo, onde os critérios de seleção e as seqüências de apresentação das séries fotográficas da coleção de imagens está exclusivamente nas mãos do criador da narrativa que a oferece pronta ao espectador, a instalação quer apresentar este tipo de problema ao usuário. Por isso, a obra é oferecida a ele de forma "inacabada". Ao usuário outorga-se o controle de certas combinações de princípios organizativos. O usuário comanda a velocidade de apresentação das imagens - do still à rápida sucessão (24 imagens por segundo) - e também a combinação de descritores que desenha o perfil da escolha - mulher/sentada, homem/balaustre etc. O usuário vê, em tempo real, uma seqüência de imagens pinçadas do banco de dados de acordo com os descritores eleitos por ele mesmo. A ele é dada, portanto, a chance de experimentar, de maneira prática,

20 O Animatoscópio foi concebido pelo artista plástico Gavin Adams, executado pelos artistas multimídia Carlos Freitas e Caio Barra Costa com o auxílio dos estagiários Frederico Hila e Mayra Saito. Foi exibido na exposição Olho Cíclico de curadoria de Solange Ferraz de Lima e Vânia Carvalho, no Museu Paulista da USP, São Paulo/Brasil em 25 de janeiro de 2004, por ocasião das comemorações dos 450 anos de fundação da cidade de São Paulo. Apoio do Fundo de Cultura e Extensão Universitária da USP, Fundo de Pesquisas do Museu Paulista da USP.

21 Número total de retratos da coleção em que a imagem não foi recortada pelo fotógrafo. 
questões da organização e estudo de uma coleção, desvelando assim discursos e artifícios da prática fotográfica que gerou os cartões de visita.

Daí sua natureza performática. ${ }^{22}$ Então, guardando uma relação de similaridade, a integração entre sistema documental, pesquisa e exposição permitem que o curador aborde simultaneamente as diversas dimensões do conhecimento que estão em jogo aquela onde corpo posado e elementos cenográficos se fundem na constituição da identidade social; aquela onde no estúdio fotográfico o indivíduo incorpora um novo modo de vida pública e privada e, finalmente, aquela onde o público engaja-se de corpo e olho na obra que pretende inseri-lo no universo do historiador e do artista plástico.

\section{Bibliografia citada}

ANDRADE, Joaquim Marçal (Org.). A Coleção do Imperador: Fotografia brasileira e estrangeira no século XIX. Rio de Janeiro: Biblioteca Nacional, 1997.

BORGES, Maria Elízia. A pintura na "Capital do Café". Franca : Unesp, 1999. e Regina Tirello. A ruina, o restauro e as pinturas murais oitocentistas do Vale do Paraíba Paulista. São Paulo: FAU/USP, 1999. Tese (Doutorado).

BRILLIANT, Richard. Portraiture. London: Reaktion Books, 1991.

BRUNO, Ernani Silva. História e tradições da cidade de São Paulo. São Paulo: Hucitec, 1984.

BURKE, Peter. Eyewitnessing. The uses of images as historical evidence London: Reaktion Books, 2001, p. 25.

CALLIGARIS, Contardo. Verdades de autobiografias e diários íntimos. Estudos Históricos, Rio de Janeiro, v. 11, n. 21, 1998, p. 43-58.

CARVALHO, Maria Cristina Wolff de. Bem-morar em São Paulo, 1880-1910: Ramos de Azevedo e os modelos europeus. Anais do Museu Paulista. São Paulo, v. 4, p. 165-200 jan./dez. 1996.

CARVALHO, Vânia Carneiro de. Gênero e artefato: o sistema doméstico na perspectiva da cultura material. São Paulo: Depto de História da FFLCH-USP, 2001. Tese (Doutorado).

22 Para o conceito de performance aqui utilizado e seus desdobramentos ver Contardo Calligaris. Verdades de autobiografias e diários íntimos. Estudos Históricos, Rio de Janeiro, v.11, no. 21, 1998, p.49; Ulpiano T. Bezerra de Meneses. Memória e cultura material: documentos pessoais no espaço público. Estudos Históricos, Rio de Janeiro, v. 11, n. 21, 1998, p. 96; Jean-Pierre Warnier. Construire la culture matérielle. L'homme qui pensait avec ses doigts. Paris: Presses Universitaires de France, 1999, p. 9-15. 
CARVALHO, Vânia Carneiro de; LIMA, Solange Ferraz de. Fotografia e cidade: da razão urbana à lógica do consumo. Álbuns de São Paulo (1887-1954). São Paulo: Mercado de Letras, 1997.

CARVALHO, Vânia Carneiro de; LIMA, Solange Ferraz de. Fotografia no Museu: o projeto de curadoria da coleção Militão Augusto de Azevedo. Anais do Museu Paulista. São Paulo. Nova Série. v. 5, p. 205-245, jan./dez. 1997.

CLARK, Anthony. Pompeo Batoni - a Complete Catalogue of his Works with an Introductory Text. London: Phaidon, 1985.

COSTA, Jurandir Freire. Ordem médica e norma familiar. 2. ed. Rio de Janeiro: Graal, 1983.

ESSUS, Ana Maria Mauad de Andrade. Sob o signo da imagem. Rio de Janeiro, 1990. Tese (Doutorado) - Universidade Federal Fluminense.

ESSUS, Ana Maria Mauad de S.A. Resgate de Memórias. In: MATTOS, Hebe Mara; SCHNOOR, Eduardo (Orgs.). Resgate: uma janela para o Oitocentos. Rio de Janeiro: Topbooks, 1995, p. 99-138.

ESSUS, Ana Maria Mauad. Resgate de Memórias. In: Eduardo Schnoor e Hebe Maria Mattos de Castro. Resgate, um janela para o oitocentos. Rio de Janeiro: Topbooks, 1995, p. 99-138.

FABRIS, Annateresa. A fotografia oitocentista ou a ilusão da objetividade. Porto Alegre, Porto Alegre, v. 5, n. 8, p. 7-16, nov. 1993.

FREYRE, Gilberto. Por uma sociofotografia. In O retrato brasileiro: fotografias da Coleção Francisco Rodrigues 1840-1920. Rio de Janeiro: Funarte/Fundação Joaquim Nabuco, 1983. p. 15-24.

FUNDAÇÃO JOAQUIM NABUCO. O sujeito em perigo: identidade fotográfica e alteridade no Brasil do século XIX até 1940. Recife: FUNDAJE/Ed. Massangana, 1992.

GRANGEIRO, Cândido Domingues. As artes de um negócio: a febre photographica. São Paulo, 1862-1886. Campinas: Fapesp/Mercado de Letras, 2000.

HOMEM, Maria Cecília Naclério. O palacete paulistano e outras formas urbanas de morar da elite cafeeira. 1867-1918. São Paulo: Martins Fontes, 1996.

IRWIN, David. Neoclassicism. London: Phaidon, 1997.

KOSSOY, Boris. Militão Augusto de Azevedo e a documentação fotográfica de São Paulo (1862-1887): recuperação da cena paulistana através da fotografia. São Paulo, 1978. Dissertação (Mestrado).

KOSSOY, Boris. Origens e expansão da fotografia no Brasil no século XIX. Rio de Janeiro: MEC/FUNARTE, 1980, p. 79.

KOSSOY, Boris; CARNEIRO, Maria Luiza Tucci. O olhar europeu: o negro na iconografia brasileira do século XIX. São Paulo: Edusp, 1994.

LAGO, Pedro Corrêa do. Militão Augusto de Azevedo. Rio de Janeiro: Capivara e Marca d'Água, 2001. 
LAURITO, Ilka Brunhilde Laurito. Retratos de um photographo. In: São Paulo em três tempos: álbum comparativo da cidade de São Paulo (1862-1887-1914). São Paulo: IMESP, 1982.

LEITE, Miriam L. Moreira. Retrato de casamento. Literatura e Memória Cultural: Anais, v. 1. Belo Horizonte, Abralic, 1991, p. 335-351.

LEMOS, Carlos Alberto Cerqueira. Alvenaria burguesa - breve história da arquitetura residencial de tijolos em São Paulo a partir do ciclo econômico liderado pelo café. 2 ed. São Paulo: Nobel, 1985.

LEMOS, Carlos Alberto Cerqueira. Casa Paulista: história das moradias anteriores ao ecletismo trazido pelo café. São Paulo: Edusp, 1999.

LEMOS, Carlos. Ambientação Ilusória. In: MOURA, Carlos Eugênio Marcondes de (Org.). Retratos quase inocentes. São Paulo: Nobel, 1983, p. 47-113.

LIMA, Solange Ferrraz de. Ornamento e Cidade - ferro, estuque e pintura mural em São Paulo, 1870-1930. São Paulo, FFLCH/USP, 2002. Tese (Doutorado).

LISSOVSKY, Maurício; AZEVEDO, Paulo César (Orgs.). Escravos brasileiros do século XIX na fotografia de Christiano Júnior. São Paulo: Ex-Libris, 1988.

MANINI, Miriam Paula. Análise documentária de fotografias: um referencial de leitura de imagens fotográficas para fins documentários. São Paulo: Escola de Comunicações e Artes da USP, 2002. Tese de (Doutorado).

McCAUleY, Elizabeth Anne. A. A. E. Disdéri and the Carte de Visite Portrait Photograph. New Haven \& London: Yale University Press, 1985.

MENESES, Ulpiano Bezerra de. A fotografia como documento. Robert Capa e o miliciano abatido na Espanha: sugestões para um estudo histórico. Revista Tempo. Universidade Federal Fluminense, 2002.

MENESES, Ulpiano T. Bezerra de. Memória e cultura material: documentos pessoais no espaço público. Estudos Históricos, Rio de Janeiro, v. 11, n. 21, 1998.

MOURA, Carlos Eugênio Marcondes de (Org.). Retratos quase inocentes. São Paulo: Nobel, 1983.

ORVELL, Miles. Photography and the Artifice of Realism. In: ORVELL, Miles. The Real Thing. Imitation and Authenticity in American Culture. 1880-1940. Chapel Hill \& London: The University of North Carolina Press, 1989, p. 73102.

PINTO, Maria Inez Machado Borges. Cotidiano e sobrevivência: a vida do trabalhador pobre na cidade de São Paulo, 1890-1914. São Paulo: Edusp / Fapesp, 1994

POINTON, Marcia. Hanging the Head. Portraiture and social formation in Eighteenth Century England. London/New Haven: Yale University Press, 1993, p. 5.

SAES, Flávio Azevedo Marques de. O campo da economia. Cadernos de História de São Paulo: os campos do conhecimento e o conhecimento da cidade. n. 1 . São Paulo: Museu Paulista da USP, 1992. p. 25-35. 
SAIA, Luís. Morada paulista. São Paulo: Perspectiva, 1972.

SANDORE, Beth Sandore (Ed.). Library Trends, v. 48, n. 2, p. 496-520, 1999.

TAGG, John Tagg. The Burden of Representation: Essays on Photographies and History. Armherst: University of Massachussetts Press, 1988.

TOLEDO, Benedito Lima de Toledo; KOSSOY, Boris. São Paulo: álbum comparativo da cidade de São Paulo. 1862-1887. São Paulo: s.e., 1981.

TOLEDO, Benedito Lima de. São Paulo, três cidades em um século. São Paulo: Duas Cidades, 1981.

VASQUEZ, Pedro. O retrato brasileiro. Rio de Janeiro: Funarte/Núcleo de Fotografia, 1983.(Catálogo de exposição).

WARNIER, Jean-Pierre. Construire la culture matérielle. L'homme qui pensait avec ses doigts. Paris: Presses Universitaires de France, 1999, p. 9-15.

\section{Bibliografia do projeto olho cíclico}

AMES, Kenneth L.; FRANCO, Barbara; FRYE, Thomas (Ed.). Ideas and images: developing interpretative History exhibits. Nashville: AASLH, 1992.

ANDERSON, David. Learning History in museums. The International journal of museum management and curatorship, n. 8, p. 357-368, 1989.

ANDERSON, Jay. Time machines: the world of living History. Nasville: AASLH, 1984.

ANDRADE, Rosane de. Fotografia e Antropologia. Olhares fora-dentro. São Paulo: Estação Liberdade / Educ, 2002

ART and Archicteture Thesaurus. Dir: Tony Peterson. New York: Oxford University Press; Paul Getty Trust, 1990.

ASSOCIATION Internationale des Musées d'Histoire (AIMH). Quel Avenir pour les musées d'histoire?. Bonn: Haus der Geschiche, 1999.

BANKS, Marcus \& MORPHY, Howard (Eds.). Rethinking Visual Anthropology. New Haven: Yale University Press, 1997.

BANN, Stephen. Views of the past: reflections on the treatment of historical objects and museums of history. In: The inventions of History: essays on the representation of the past. Manchester: Manchester University Press, 1990, p. 122-147.

BARNARD, Malcolm. Approaches to understanding visual culture. New York: Palgrave, 2001.

BELCHER, Michael. Exhibitions in museums. Leicester: Leicester University Press, 1991.

BENNET, Tony. The exhibitionary complex. In: DIRKS, Nicholas B.; ELEY, EleY.; ortner, Sherry B. eds. Culture, power, history: a reader in contemporary social theory. Princenton: Princenton University Press, 1994, p. 123-154. 
BESSER, Howard. Visual Access to Visual Images: The UC Berkeley Image Database Project. Library Trends, v. 38, n. 2, p. 787-98, 1990.

BLATTI, O. (Ed.). Past meets present: essays about historic interpretationand public audiences. Washington: Smithsonian Institution Press, 1987.

BOURDIEU, Pierre; HAACKE, Hans. Livre-troca: diálogos entre ciência e arte. Rio de Janeiro: Bertrand Brasil, 1995.

BRENNAN, Teresa; MARTIN, Jay (Eds.). Vision in context. Historical and contemporary perspectives on sight. London: Routledge, 1996.

BRYSON, Norman; HOLLY, Michael Ann; MOXEY, Keith (Eds.). Visual culture. Images and interpretations. Hanover HN: Wesleyan University Press / The University Press of New England, 1994.

BURGIN, Victor. Something about photography theory. In REES, A. L.; BORZELLO, F. (Eds.). The New Art History. London: Camden Press, 1986, p. 41-54.

BURKE, Peter. Eyewitnessing. The uses of images as historical evidence. London: Reaktion Books, 2001.

CARDOSO, Ciro F.S. \& MAUAD, Ana Maria. História e imagem: o exemplo da fotografia e do cinema. In CARDOSO, Ciro F.S. \& VAINFAS, Ronaldo (Orgs.). Domínios da História. Ensaios de teoria e metodologia. Rio de Janeiro: Campus, 1997, p. 401-418.

CASSIDY, Brendan. Iconography in Theory and Practice. Visual Resources, v. 11, p. 323-348, 1996.

CHANEY, David C. Contemporary socioscapes. Books on Visual Culture, Theory, Culture E Society (London), v. 17, n. 6, p. 111-24, 2000.

CHAPLIN, Elizabeth. Sociology and visual representation. London: Routledge, 1994.

CHEN, Hsin-Liang; RASMUSSEN, Edie M. Intellectual Access to Images. Library Trends, v. 48, n. 2, p. 291-302, 1999.

COSTA, Helouise. Aprenda a ver as coisas: fotojornalismo e modernidade na Revista O Cruzeiro. São Paulo, 1992. Dissertação (Mestrado) - Escola de Comunicações e Artes da USP.

COSTA, Helouise. Um olhar que pensa: estética moderna e fotojornalismo. São Paulo: 1998. Tese (Doutorado) - Faculdade de Arquitetura e Urbanismo da USP.

CRARY, J. Suspensions of Perception. Londres, MIT Press, 1999.

CRARY, J. Techniques of the Observer. Londres, MIT Press, 1992.

DANET, Brenda; KATRIEL, Tamar. No Two Alike: Play and Aesthetics in Collecting. In: PEARCE, Susan (Ed.). Interpreting Objects and Collections. London: New York: Routledge, 1996, p. 220-239.

DEBORD, Guy. La société du spectacle. Paris: Gallimard, 1992. 
DOOLEY, Jackie. Processing and Cataloging of Archival Photograph Collections. Visual Resources, v. 11, p. 85-101, 1995.

EDITORIAL: ICONCLASS Projects. Visual Resources, v. 7, n. 1, p. VII-XIII, 1990.

EDWARDS, Elizabeth. Antropologia e fotografia, Cadernos de Antropologia e Imagem (Rio de Janeiro), v. 2, p. 11-28, 1996.

ELKINS, James The object stares back. On the nature of seeing. New York: Simon \& Schuster, 1996.

ELKINS, James. Preface to the book 'A skeptical introduction to Visual Culture', Journal of Visual Culture (London), v. 1, n. 1, p. 93-100, 2002.

ELKINS, James. The domain of images. Ithaca: Cornell University Press, 1999.

EMMISON, Michael; SMITH, Philip. Researching the visual. Images, objects, contexts and interactions in social and cultural inquiry. London, Sage, 2000.

ESSUS, Ana Maria Mauad de S.A. O Olho da história: análise da imagem fotográfica na construção da memória. Acervo - Revista do Arquivo Nacional, Rio de Janeiro, v. 6, n. 1-2, p. 25-40, 1993.

ESSUS, Ana Maria Mauad de S.A. Resgate de Memórias. In: MATTOS, Hebe Mara; SCHNOOR, Eduardo (Orgs.). Resgate: uma janela para o Oitocentos. Rio de Janeiro: Topbooks, 1995, p. 99-138.

ESSUS, Ana Maria Mauad de S.A. Sob o signo da imagem. Rio de Janeiro: 1990. Tese (Doutorado) - Universidade Federal Fluminense.

EVANS, Jessica; HALL, Stuart (Eds.). Visual culture : the reader. London: Sage, 1999.

FELDMAN-BIANCO, Bela; LEITE, Miriam L.Moreira (Orgs.). Desafios da imagem: fotografia, iconografia e vídeo nas ciências sociais. Campinas: Papirus, 1998.

Freedberg, David, The power of images. Studies in the history and theory of response. Chicago: The University of Chicago Press, 1989.

FUNARTE/IBAC et. al. Manual para catalogação de documentos fotográficos. Rio de Janeiro: Funarte-IBAC/Fundação Biblioteca Nacional/Museu Histórico Nacional/Museu Imperial de Petrópolis/Cpdoc-FGV, 1993.

FYFE, Gordon; LAW, John (Eds.). Picturing power. Visual depiction and social relations. London: Routledge, 1988.

GAMBONI, Dario. Histoire de l'art et 'réception': remarques sur l'état d'une problématique, Histoire de l'art (Paris), p. 9-14, oct. 1996.

GARFIELD, D. Making the Museum Mine: an interview with Fred Wilson, in Museum News, maio/jun. 1993. p. 47-49.

GARNIER, François. Thesaurus Iconographique. Système Descriptif des Représentations. Paris: Ministère de la Culture/ Le Léopard D’Or, 1984. 
GASKELLl, Ivan. Vermeer's wager. Speculations on art history, theory and art museums. London: Reaktion Books, 2000.

GERVEREAU, Laurent. Voir, comprendre, analyser les images. Paris: La Découverte, 2000.

GREENBERG, Reesa; FERGUSON, Bruce W.; NAIRME, Sandy. Thinking about Exhibitions. London/New York: Routledge, 1996.

GRIFFITHS, Gareth; PORTER, Gaby. Photographs and Films. In: FLEMING, David; PAINE, Crispin; RHODES, John G. Social History in Museums. A Handbook for Professionals. London: HMSO, 1993. p. 158-165.

GRIMSHAW, Anna. The ethnographer's eye. Ways of seeing in modern Anthropology. Cambridge: Cambridge University Press, 2001.

HEIDORN, P. Bryan. Image Retrieval as Linguistic and Nonlinguistic Visual Model Matching. Library Trends, v. 48, n. 2, p. 303-25, 1999.

HEIDORN, P. Bryan. Image Retrieval as Linguistic and Nonlinguistic Visual Model Matching. Library Trends, v. 48, n. 2, p. 303-25, 1999.

HEYWOOD, Ian; SANDYWELLl, Barry (Eds.). Interpreting visual culture. Explorations in the hermeneutics of the visual. London: Routledge, 1999.

HOOPER-GREENHILL, Eilean ed. Museum, media, message. London: Routledge, 1995.

HUDRISIER, Henri. L'iconothèque: documentation audiovisuelle et banques d'images. Paris: Documentation Française, 1982.

JAY, Martin. Cultural relativism and the visual turn, Journal of Visual Culture (London), v. 1, n. 3, p. 267-279, 2002.

KARP, Ivan; LAVINE, Steven EDS. Exhibiting cultures; the poetics and politics of museum display. Washington: The Smithsonian Institution Press, 1991.

KOSSOY, Boris. Fotografia \& história. 2. ed. rev. São Paulo: Ateliê Editorial, 2001.

KOURY, Mauro Guilherme Pinheiro. A imagem nas ciências sociais do Brasil: um balanço crítico, BIB (São Paulo), n. 47, p. 49-63, 1999.

KRAUSS, R. The Optical Unconscious. Londres: MIT Press, 1994.

LISSOVSKY, Maurício. O dedo e a orelha: ascensão e queda da imagem nos tempos digitais. Acervo - Revista do Arquivo Nacional, Rio de Janeiro, v. 6, n. 1/2, p. 55-74, jan.-dez 1993.

MENESES, Ulpiano T. Bezerra de et al. Como explorar um museu histórico. São Paulo: Museu Paulista/USP, 1992.

MENESES, Ulpiano T. Bezerra de. Do teatro da memória ao laboratório da História: a exposição museológica e o conhecimento. Anais do Museu Paulista. São Paulo. N. Ser. v. 2, p. 9-42 jan./dez. 1994. 
MENESES, Ulpiano T. Bezerra de. Fontes Visuais, Cultura Visual, História Visaul : balanço provisório, propostas cautelares. Revista Brasileira de História. 2003 (no prelo).

MENESES, Ulpiano T.Bezerra de. A fotografia como documento. Robert Capa e o miliciano abatido na Espanha: sugestões para um estudo histórico, Tempo (Niterói), 2003 (no prelo).

MICHEL Ann; MOXEY, Keith, eds. Visual culture. Images and interpretations. Hanover: University Press of New England / Wesleyan University Press, 1994, pp. 83-104.

MIRZOEFF, Nicholas (Ed.). The visual culture reader. London: Routledge, 1998, pp.14-26.

MIRZOEFF, Nicholas (ed.). Visual culture reader. London: Routledge, 1998.

MIRZOEFF, Nicholas. An introduction to visual culture. London: Routlege, 1999.

MITCHELL, W.J.T., Showing seeing: a critique of visual culture, Journal of Visual Studies (London), v. 1, n. 2, p. 165-182, 2002.

MONPETIT, Raymond. Exposer le savoir et savoir exposer: les champs disciplinaires de la muséologie. In: GENDREAU, Andrée (Ed.). Colloque Museólogie et champs disciplinaires. Actes. Quebec: Musée de la civilization, 1990. p. 11-22.

NELSON, Robert S. (Ed.). Visuality before and beyond the Renaissance. Cambridge: Cambridge University Press, 2000.

NICOLAS, Alain. Ed. Nouvelles muséologies. Marselle: Association Muséologie Nouvelle et Experimentation Sociale, 1985. p. 89-101.

PAIVA, Eduardo França. História E imagens. Belo Horizonte: Autêntica, 2002.

PEARCE, Susan M. Museums Objects and Collection. A Cultural Study. London: Leicester University Press, 1992.

RICE, Danielle. Vision and culture: the role of museum in visual literacy. The Journal of Museum Education, v. 13, n. 3, p. 13-17, 1988.

SHARPE, Elizabeth. The visitor as historian: the Hands on History Room experience. The Journal of Museum Education, v. 12, n. 2, p. 8-11. Sping/Summer, 1987.

SORLIN, Pierre. Enganosas e indispensáveis, as imagens, testemunhas da História, Estudos Históricos (Rio de Janeiro), n. 13, p. 81-95, 1994.

SOUSA, Jorge Pedro. Uma história crítica do fotojornalismo ocidental. Chapecó/Florianópolis: Editora Grifos/Letras Contemporâneas, 2000.

SRIHARI, Rohini K.; ZHANG, Zhongfei. Exploiting Multimodal Context in Image Retrieval. Library Trends, v. 48, n. 2, p. 496-520, 1999.

STURKEN, Marita; CARTWRIHT. Practices of looking. An introduction to visual culture. Oxford: Oxford University Press, 2001. 
TAGG, John. The discontinuous city. Picturing and the discursive field. In : BRYSON, Norman; HOLLY, Michael Ann; MOXEY, Keith (Eds.). Visual culture. Images and interpretations. Hanover: University Press of New England / Wesleyan University Press, 1994, p. 83-104.

TURNER, James M. Subject Access to Pictures: Considerations in the Surrogation and Indexing of Visual Documents for Storage and Retrieval. Visual Resources, v. 9, p. 242-271, 1993.

VIEL, Annette; DE GUISE, Céline, eds. Musée-séduction, musée-reflexion. Quebec: Musée de la Civilization, 1992.

VIRÍLIO, Paul. A máquina de visão. Rio de Janeiro: José Olympio, 1994.

VOVELLE, Michel. Imagens e imaginário na História. Fantasmas e certezas nas mentalidades desde a Idade Média até o século 20, trad. bras. São Paulo: Ática, 1997.

WAAL, H. van de. ICONCLASS. An Iconographic Classification System. Edited by L.D.Couprie. Amsterdam: North-Holland Pub. Co., 1974.

WALTER, John A.; Chaplin, Sarah. Visual culture: an introduction. Manchester: Manchester University Press, 1997.

ZINKHAM, Helena; PARKER, Elisabeth Betz (Eds.). Descriptive Terms for Graphic Materials: Genre and Physical Characteristic Headings. Washington: Library of Congress, 1986. 